DOI: $10.1515 /$ hssr -2017-0005

HSS VI.1 (2017)

\title{
A Universal Moral Grammar?
}

Laura Carmen Cutitaru*

"Alexandru Ioan Cuza" University of Iasi, Romania

\begin{abstract}
This paper describes the main drawbacks of extrapolating Noam Chomsky's hypothesis about the existence of a Universal Grammar of language to the realm of morality as illustrated in Marc Hauser's 2006 volume, Moral Minds.

Keywords

Transformational Generative Grammar (T.G.G.), Universal Grammar (U.G.), Universal Moral Grammar, Linguistic universals, Moral universals
\end{abstract}

Noam Chomsky's linguistic philosophy seems to have at its core two fundamental truths: a) every human being on Earth gets to master their mother tongue no matter how stupid they are, and b) every human being on Earth has the ability to produce and understand new utterances that look like nothing they have heard before. The explanation proposed by the American linguist stands in bold contrast to behaviorist opinions according to which language is a set of habits based on associations between words and objects. Instead, it hypothesizes upon a built-in mechanism called L.A.D. (Language Acquisition Device) that every newborn is naturally endowed with and which sensitizes him/her to the language spoken in the environment. The L.A.D. operates on the Universal Grammar (U.G.), a master-code including universal principles and parameter-setting possibilities.

\footnotetext{
*Faculty of Letters, “Al. I. Cuza” University of Iasi, 11 Carol I Blvd, 700506, Iasi, Romania; lauracutitaru@yahoo.com
} 
Chomsky's endeavors were many times likened to a "revolution" in linguistics, especially by non-linguists, who were enthused by the novelty of this approach and its sharp opposition to traditional views (i.e. Bloomfieldian structuralism). With the generative enterprise, the point of focus in linguistic study was represented by mental aspects. Therefore, it is not surprising that researchers in connected social fields looked with hope to what was going on in linguistics. Extrapolations to other types of human behavior became quite common. This was further enhanced by the amplitude of generativist research and the generous funding of such studies in American universities, which brought more credit upon it than its results entitled it to.

One such extrapolation regards the moral system developed by human beings. The fundamental point made by moral philosophers is that, just like in the case of one's mother tongue that one always succeeds in acquiring, all human beings are able to acquire moral codes. If there is a language faculty in our brains, then the language we acquire depends essentially on the auditory input in our environment, and the process is culturally motivated. Similarly, if everybody has an idea of what is right and wrong, then the concrete deeds - good or bad - that we are allowed to do are dictated by our environment, being culturally motivated in their turn.

This parallel between morals and language (also called "the linguistic turn") was first suggested by the American moral and political philosopher John Rawls. He believed in the generativists' hypothesis according to which any speaker was able to instinctively recognize grammaticality in utterances formulated in their mother tongue, without having conscious access to the rules it was governed by. He took matters further onto the realm of moral philosophy hypothesizing that, in a similar way, we all had a sense of justice that could not be fully explained by principles of learning.

Rawls's suggestion that Chomsky's generative approach to language could be used by theorists of morality ${ }^{1}$ was taken over and investigated by modern American authors like John Mikhail at Georgetown University, Washington, and Marc Hauser, former Harvard psychologist. In a 2011 interview ${ }^{2}$, Mikhail says that our moral judgments could have an innate fundament, i.e. a system of principles and rules similar to the Universal Grammar in linguistics. Children too, he says, seem to know more than they are supposed to at their age, being a kind of intuitive lawyers, making 
sophisticated moral judgments based on principles used not only by adults but also by judicial systems (for example, intention).

If John Mikhail is quite careful about term-usage and qualifies his discourse in a moderate tone, evolutionist biologist and primatologist Marc Hauser fully embraces the linguistic analogy, dedicating to it a very voluminous book. His Moral Minds (2006) closely tracks down the language-morality parallel, constantly forcing its common points.

Hauser starts his demonstrations from linguistic combinatoriality: (meaningless) phonemes combine and make up syllables that combine into (meaningful) words that come together and form phrases, sentences, and texts. In a similar way, actions seem to organize hierarchically: taken separately, "many actions" make no sense (like phonemes), but when combined, they "are often meaningful" and represent an agent's purposes, his means, the consequences of his actions. Therefore, something organized on a hierarchically superior level is created, and it is called "event". We understand from this comparison that a phoneme, which is the minimal unit of analysis in language, finds its correspondent in action, presumably the minimal unit of analysis in ethics ${ }^{3}$.

Man's capacity to create events suggests that morality is based on a system of general principles and rules, and not on specific acts. It is irrelevant if the author and the victim of an attack are named John and Fred, respectively, since people evaluate this event in abstract terms like agent, action, receiver, consequence, moral evaluation (like slots in a machine, we should say, that are to be filled with appropriate items: in linguistics Noun Phrase NP, Verbal Phrase VP, and so on); in this specific case of morals, John, attacks, Fred, pain, and impermissible fill in the abstract terms aforesaid.

A second parallel with language comes from the decomposition of this principle into components. In generative linguistics, the design feature of creativity (productivity) describes man's capacity to combine elements of a finite set (words in lexis) in order to obtain a (theoretically) infinite number of messages. Similarly, Hauser says, we combine actions, causes and consequences in morality.

The author formulates the difficult task of researchers to answer fundamental questions that have already been asked about language: how does the moral faculty evolve? Does the environment provide children 
with enough input in order for them to build a moral system by imitation or, on the contrary, do they seem to have innate abilities? Does anyone teach them explicitly or do they pick it up as they go? Is there a cut-off age, beyond which they have no chance to develop a moral system?

He deplores the fact that, unlike in linguistics, where (he thinks) armies of researchers have put together extensive catalogs of what people say and understand in different languages, in ethics there is no such equivalent enterprise on what people do and think in morally relevant situations.

As for the question of how the moral faculty evolved, Hauser suggests that, just like in language study, the answer should be looked for by decomposing the faculty into its components, identifying the common points with the animal world, and finding the uniquely human feature that distinguishes the human race from the animal kingdom. After which, the only problem left to be solved is whether this uniquely human feature is exclusively reserved to the moral faculty or, on the contrary, it is used by other systems of knowledge as well.

Speaking about the potential existence of universal morals (paralleling linguistic universals), Hauser sets forth three possible approaches:

On the one end of the spectrum is a nativist position that puts precise moral rules or norms in the newborn's head. She is born knowing that killing is wrong, helping is good, breaking promises is bad, and gratuitously harming someone is evil. On the opposite end of the spectrum is the view that our moral faculty lacks content but starts us off with a device that can acquire moral norms. With this view, there are no rules and no content, only general processes for acquiring what nurture hands us. In the middle is the view that we are born with abstract rules or principles, with nurture entering the picture to set the parameters and guide us towards the acquisition of particular moral systems. The middle view is the one I favor. / .../ something about the human brain allows us to acquire a system of moral norms. (Hauser, 2006: 165).

Although Hauser claims he uses parallels to language when he points out these three approaches, there is no such threefold way in linguistic study. Rather, only the nature-nurture debate. The nativist position has never claimed that a baby is born knowing a language, but (what Hauser says it is the opposite end of the spectrum) having a Language Acquisition 
Device (L.A.D.) hard-wired in its brain that enables the acquisition of whatever linguistic system is used by speakers around. There is no content to it, true, but there are principles and rules, while speech in the environment triggers parameters' setting. Nurturists (behaviorists) are really at the end of the spectrum, favoring learning by mere imitation and saying nothing about the minds of the speakers.

While this is quite a departure from reality, in what comes next Hauser does indeed closely follow research directions and arguments brought by Chomskyan researchers of language, often to the point of overlapping. For example, taking over Rawls's idea, he says that

All humans are endowed with a moral faculty - a capacity that enables each individual to unconsciously and automatically evaluate a limitless variety of actions in terms of principles that dictate what is permissible, obligatory, or forbidden (Hauser, 2006: 36).

And that is because

Every speaker of a language can make instantaneous grammaticality judgments, decisions about whether a particular sentence is well formed or ill formed. (Hauser, 2006: 37).

First of all, there is no such thing as "a limitless variety of actions". There are as many actions as there are verbs in a language to name them. Secondly, the allegedly numerous moral principles underlying man's capacity to declare something permissible, obligatory or forbidden really boil down to one golden rule or principle: do unto others as you would have them do unto you. The rest is just splitting hairs. Thirdly, the term grammaticality was originally meant to mean "compatible with the U.G.", not "being correct or incorrect". It grew to mean just that, however, because no one had any idea what something compatible to the U.G. might look like. Chomsky's approach was deductive (opposed to the traditional inductive one), setting forth hypotheses and then having researchers look for evidence to back them up. The one under scrutiny has always been competence (what the speaker unconsciously knows about his/her mother tongue), never performance (i.e. the actual speech of the 
speaker); in actual research however, how was one supposed to go about finding evidence to testify to something unknown to the speakers themselves? Fourthly, how right one is about sentences being well or ill formed very much depends on one's literacy (read "nurturing"), something that is fundamentally at odds with the premises of nativism.

Hauser describes a very detailed anatomy of what he calls "the Rawlsian creature", in ten features. The first four refer to the moral information stored by adults - unconscious in nature (just like competence), therefore inaccessible voluntarily: 1) principles guiding our moral judgments underlie our moral faculty; 2) each generates quick automatic judgments about actions or events being permissible, forbidden or obligatory; 3) these principles are inaccessible to conscience; 4) they rely on experiences independent of any sensorial origin and of any form of language (spoken, written, signed).

The next three are characteristics related to development: 5) the principles of this moral U.G. are innate; 6) the native moral system develops quickly, effortlessly, without any (or with little) need of explicit training, while parameters' setting is ensured by living in a certain moral environment; 7) the moral faculty constrains the series of possible ethical systems.

The last three refer to evolutionist issues: 8) only the principles of the moral U.G. are uniquely human and are reserved exclusively to the moral faculty; 9) in its functioning, the moral faculty interacts with other abilities (speech, sight, hearing, emotions, memory etc.); 10) consequent to the moral faculty's dependence on specialized neural circuitry, any damage to it may lead to deficits in both moral judgment and moral behavior.

Let us examine them now, but not in this order since some of them are intertwined. Feature ten can be discussed without reference to the other nine. Specialized literature has indeed proven that, with numerous cases of chronic violent or criminal behavior, CAT scans of the brains of such subjects show definite cerebral lesions; severe brain trauma can lead to changes not only in the behavior but also in the character (personality) of the sufferer ${ }^{4}$, that some lesions leave intact the capacity to judge what is right but not to do what is right. Whether the linguistic analogy works here and how far it can go - we can only speculate on. Chapter four in 
Hauser's book is entitled "The Moral Organ", to parallel the "language organ" (the left perisylvian fissure), where the cerebral areas involved in language processing can be found. But neurologists say we cannot speak of a moral organ - it seems it would be too much to say there are neural circuits dedicated exclusively to this human endowment. American neurologist Antonio Damasio (2010) believes that ethical behavior does indeed depend on the activity of certain cerebral systems, but these are not "centres", and they are most certainly destined to memory processes, decision-making, and creativity.

Features four and nine refer to something they have in common but seem to contradict each other: on the one hand, the moral faculty is said to rely on experiences that do not depend on anything material/physical (bodily senses), having an immaterial input, of a purely mental kind; on the other hand, its functioning implies interaction with other human abilities (like hearing, speech, vision etc.). My strongest objection is that it is utterly illogical (and impossible) to have in our brains a system that has an immaterial kind of input and a material type of output. It cannot interact selectively, feeding on its own inborn products while interacting with the other biological systems. Medicine and biology today know nothing of any mental activity which should not have a neural basis. There is no place in our brains, no matter how small or hidden, so as to be isolated from our other biological structures and not get any information/input. If there were, then it could not interact with anything. Therefore, feature four and nine nullify each other.

Remember that everything is a faithful extrapolation: replace "moral" with "linguistic" and there you have it. Does this mean that, in language study, features four and nine would hold? The answer is - only feature nine. Referring strictly to the spoken type of language (because there is also a signed type of language, for the deaf-mute, and the Braille system for the blind), the capacity to speak a mother tongue depends - equally and crucially - on normal hearing and on a normal articulatory system. The ability of writing (language in its graphic, visual representation) naturally depends on vision.

If this can be extrapolated to morality remains something to be proven. But feature number four is not true for language, so neither is it for morality. It originates in an idea that Chomsky had when he called 
the generativist enterprise a Cartesian type of linguistics, thus indicating that some of the generativist tenets found their inspiration in the $17^{\text {th }}$ century philosophy of René Descartes. Chomsky maintains that the most obvious and characteristic feature of human behavior as opposed to animal behavior is stimulus-freedom. This was also mentioned by Descartes (in his Letter to More) when he questioned the reasons why animals do certain things and anticipated Pavlov's and Skinner's conditioning.

But, while this argument was used by Descartes to prove there was a mind/reason/intellect inside the human being that separated us from the animal kingdom, its place is taken by language in Chomsky's philosophy: it is language that sets us apart. And the idea that language, as a mental reality, does not depend on sensorial input comes from Descartes directly: the human body relies on senses, it is governed by instincts, it is made of flesh, it is divisible and it exists in the physical space. In contrast, the mind has a different nature, and it transcends space as an immaterial indivisible entity. Beside sensorial input from the senses, the mind can generate its own ideas - says Descartes - which come independently of the stimuli in the environment and sometimes even against the will of the mind-bearer himself. These he calls innate (Descartes, 1980: 61).

Feature number five draws on this innateness issue. Hauser says the principles of our moral faculty are innate and they are the ones that enable us to generate quick automatic judgments about the morality of an action. First of all, common sense indicates that we are all born with talents (proneness for certain achievements), predispositions (proneness for certain diseases), and inclinations (proneness for some type of behavior). The comical separation of mental activities into faculties (just like in the $18^{\text {th }}$ century phrenology $)^{5}$ should stop. If there is a talent for language, for mathematics, for music, or for any other suchlike mental production (morality is too abstract to be included here), it relies on principles that belong to the mind as a whole and come into play in whatever mental activity calls upon them.

Secondly, it is unsure how "quick" and "automatic" (feature number two) these judgments really are. The golden rule (do unto others as you would have them do unto you) is easy to apply in simple situations. The 
more complex a situation becomes, the more thought, details, and weighing it requires. Hauser appeals to results of tests involving circumstances invented by other philosophers: would you push someone in front of a running trolley if you knew that it was the only way to save the lives of other five unsuspecting people standing on the track? If you are in a driverless trolley that is going to run over five people unless you derail it, what do you do? If, by derailing it, you kill a man but other five get to live, what do you do? And so on.

A natural objection is: these are no real-life situations that could enable one to draw valid data on morality. The informants give theoretical answers because one never truly knows what one would do in a certain situation. Dramatic circumstances trigger all types of surprising human behavior. In language study, linguists failed to access the speakers' (unconscious) competence by asking them what they thought about this or that. In morality, a similar enterprise is bound to have the same fate.

Then, we are told the purpose of such tests was to reach the distinction between "to kill" and "to let die", which underlies many decisions in bioethics, especially in sensitive issues like euthanasia or abortion. What are the factors mediating our decision-making? The answers given by informants show that, no matter what they think they might decide, they can hardly explain their choice: some invoke intuition, some gut feeling, or impulse of the moment.

Based on people's inability to argument their decisions clearly (maybe some only have a verbalization problem!) Hauser infers feature number three, according to which

/.../ much of our knowledge of morality is similarly intuitive, based on unconscious and inaccessible principles for guiding judgments of permissibility (Hauser 2006: 125).

He compares this intuitive moral knowledge with the intuitive knowledge everybody has about language, physics, psychology, biology, and music. We all know, says Hauser, that two solid objects cannot take the same space at the same time or that a solid object will fall unless held, and we know this without any special training in physics and quite 
unaware of our knowledge. I should say this comes from mere observation (experience). Other types of knowledge obviously come from education: just think of the fascinating insights an illiterate person can have about their own biology or psychology (or language, as a matter of fact!).

Feature number eight makes an equally absurd claim: only the principles of the universal moral grammar are uniquely human and reserved exclusively for the moral faculty. As long as the existence of a universal grammar (in T.G.G. acception of the terms) remains a hypothesis, what is the use of making ever subtler suppositions about other types of the same sort. For the same reason, we can also include here feature number seven about restrictions of U.G. on possible systems, be they linguistic or moral.

Feature number six tells us that the Rawlsian creature develops its moral system the way it acquires its mother tongue - quickly, effortlessly, in the absence of or with very little specific training. The truth is that, in comparison to language acquisition, a moral system develops very differently. While in the former case, DNA pre-specifications and environmental influence work together towards a successful end, we can learn a moral system not because we are hard-wired to, but because human beings can learn anything. The type of morality depends completely on where we grow up, the same way one cannot learn Chinese if raised among Africans. Hauser admits, however, that the parameters of the type of morality are set culturally.

Raising a child for some time in an environment in which she/he cannot notice (and be explained) the right and wrong in other people's behavior, and then see what has happened, if he/she has "naturally" developed a moral system or not is unarguably a forbidden experiment. (This resembles a very old popular belief according to which, if a newborn was not exposed to any spoken language at all, it would eventually start speaking an ancient language like Greek or Hebrew).

Unlike language, learning moral values does require explicit advice and guidance from parents or caretakers. Punishment for bad deeds and praises for good ones are welcome and necessary. Personal examples likewise. True development of a moral code depends on the individual psychic maturational process, having nothing to do with biological age: 
there is no cut-off age, as there is in the case of language (in which, if one has not acquired a mother tongue before roughly the onset of puberty, one is doomed to never be able to develop grammar). An extrapolation to morality is not possible: looking at the other end of the spectrum, at chronic cases of criminal behavior, we can see that, many times, a lifelong process of education and reeducation seems to not be enough to correct antisocial manifestations.

Beside all this, if in the case of the mother tongue one has no choice and uses it in everyday communication within a social group, things are different for morality since one can know all the rules of good cooperation and living yet choose to break them systematically. So that, in the end, only feature number one stands victorious: principles guiding moral judgment underlie our moral faculty. This is something commonsensically true, since everything we do is guided by principles that unrestrictedly belong to the mind as a whole.

When asked what he believed about the extrapolation of his nativist hypothesis to human moral abilities, Noam Chomsky answered that an analogy was not to be dismissed if we took into account man's constant making of (mostly convergent) moral judgments in new contexts. But, after half a century of research that failed to prove that one could say more about a speaker's language if one looked at their mind, I believe this is as far as one can take the moral analogy.

\section{References}

Damasio, A. (2010). În căutarea lui Spinoza. Cum explică știința sentimentele. București: Humanitas.

Descartes, R. (1991). Letters. In The Philosophical Writings of Descartes, vol. III (Correspondence), Cambridge: Cambridge University Press.

Descartes, R. (1980). Discourse on Method and Meditations on First Philosophy. Indianapolis: Hackett Publishing Company.

Hauser, M.D. (2006). Moral Minds. The Nature of Right and Wrong. London \& New York: Harper. 
${ }^{1}$ Here is one from statistics. In his Thinking, Fast and Slow (2011), Nobel Prize winner Daniel Kahneman recalls a reunion with Professor Amos Tversky who told his class about an ongoing research project at the University of Michigan: are people good intuitive statisticians as they are intuitive grammarians?

2 The interview was taken by David Edmonds and Nigel Warburton, see philosophybites.com/2011/06/john-mikhail-on-universal-moral-grammar.btml

3 Here is how phonemic combinatoriality finds in counterpart in music "grammar": inspired by the U.G. theory, in a series of conferences held at Harvard, composer and conductor Leonard Bernstein speculates upon the existence of a universal musical grammar operating subconsciously, and he urges researchers to pursue it. One such result is a 1983 book by linguist Ray Jackendoff and musical theorist Fred Lerdahl (A Generative Theory of Tonal Music). They identify, as the title says, a generative grammar of tonal music reached by comparing formal and extra-formal means common to both language and music. For example, both imply using binary sequences of sounds - phonemes in language, tones in music; they have a hierarchical organization, and use recursion.

${ }^{4}$ One of the most famous cases is that of Phineas Gage, described in American neurologist Antonio Damasio's Descartes' Error (1994).

${ }^{5}$ Phrenology was founded by Franz Josef Gall, a Viennese physician, at the beginning of the $19^{\text {th }}$ century; it held that the mind was made up of 27 separate, innate faculties (e.g. for music, for speech, for religion, and so on), each located in a specially designed place in the brain.

\section{Biographical note}

Laura Carmen Cutitaru is currently teaching English language and linguistics as Associate Professor with the Department of English Language and Literature at the "Alexandru Ioan Cuza" University of Iasi, Romania. She has translated six books (Frederick Kellogg, O istorie a istoriografiei române; Frederick Kellogg, Drumul României spre independenţă ; Ion Popescu-Sireteanu, The Town of Siret and Its Environs; Nicolae Dascălu, Pilgrim in Iassi; Virgil Nemoianu, Postmodernismul și identitățile culturale. Conflicte și coexistență; Charlie Chaplin, Un comic vede lumea), and authored two (Elements of Psychology and Pathology of Language, 2007; Naratorul la rampă. O incursiune in poetica jamesiană, 2012). 